\title{
PERAN MEDIASI ORGANIZATIONAL COMMITMENT PADA PENGARUH JOB SATISFACTION TERHADAP TURNOVER INTENTION PADA KARYAWAN PT PANCAPUTRA MITRATAMA MANDIRI
}

\author{
Gita Kusuma Dewi \\ Universitas Negeri Surabaya \\ gitadewi16080574143@mhs.unesa.ac.id \\ Budiono \\ Universitas Negeri Surabaya \\ ec.budiono@unesa.ac.id
}

\begin{abstract}
PT Pancapaputra Mitratama Mandiri is an authorized lubricant distributor of PT Shell Indonesia. The company was founded in 2004. The company is a distributor office of Shell Lubricants products for the industrial and transportation scope in the East Java Region. This research purposes to test and explain the impact of job satisfaction on turnover intention through organizational commitment as a mediator variable at PT Pancaputra Mitratama Mandiri. The approach adopted in this study is quantitative, while the sampling technique in this study is saturated sample with the number of all employees of PT Pancaputra Mitratama Mandiri as respondents who were taken part as many as 32 employees. Data on this research were analyzed making use of Partial Least Square (PLS) with the assistance of SmartPLS 3.0. software on the computer. The outcomes further revealed a significant negative relationship between Job Satisfaction and Organizational Commitment on Turnover Intention. The results provide a conclusion that Organizational Commitment mediates the influence of Job Satisfaction on Turnover Intention, the results discover that the Job Satisfaction has an indirect effect that is larger than the direct influence on Turnover Intention.
\end{abstract}

Keywords: job satisfaction; organizational commitment; turnover intention.

\section{PENDAHULUAN}

Perusahaan dalam menjumpai persaingan global yang semakin ketat di periode Revolusi Industri 4.0 harus dapat menaikkan daya saing di bidang bisnis yang menjadi wilayah operasinya. Untuk meningkatkan daya saing bisnis, perusahaan harus memiliki aspek penting yaitu sumber daya manusia yang berkompeten dan bermutu. Dengan demikian, perusahaan perlu mengurus dan mengatur sumber daya manusia dengan sistematis agar efektivitas dan efisiensi perusahaan mengalami peningkatan (Diputra dan Mujiati, 2016).

Sumber daya manusia merupakan pengelola utama dalam konteks menjalankan aktivitas roda organisasi agar terus menerus bergerak secara dinamis (Sapruni, 2014). Sumber daya manusia merupakan faktor yang sangat penting bagi kemajuan suatu perusahaan. Perusahaan membutuhkan sumber daya manusia dengan daya saing tinggi di dalam situasi dan kondisi apapun. Demi kemajuan perusahaan, sumber daya manusia yang ada di perusahaan harus memprioritaskan ketaatan pada peraturan di perusahaan, sikap terpuji, serta loyalitas kerja tanpa batas (Nanulaitta, 2018).

Karyawan adalah sumber daya yang penting bagi perusahaan (Bayraktar dan Sencan, 2017). Lestari (2015) menyatakan bahwa karyawan adalah aset utama perusahaan yang menjadi perencana dan pelaku aktif dari setiap aktivitas organisasi. Salah satu hal tepenting bagi perusahaan yaitu karyawan yang tepat dan cocok serta sesuai dengan kebutuhan perusahaan. Ketika perusahaan telah menemukan karyawan yang cocok dan selaras dengan kebutuhan perusahaan, maka dengan itu perusahaan harus memperhatikan kepuasan kerja karyawannya, lantaran hal tersebut akan berpengaruh dan berdampak pada perpindahan karyawan.

Job satisfaction adalah bentuk perasaan intens yang memuaskan atau sebaliknya saat karyawan memandang pekerjaannya. Upaya yang lebih besar terhadap pekerjaannya akan timbul dari perasaan 
Gita Kusuma Dewi \& Budiono. Peran Mediasi Organizational Commitment pada Pengaruh Job Satisfaction terhadap Turnover Intention pada Karyawan PT Pancaputra Mitratama Mandiri.

puas dan nyaman dari karyawan dengan kondisi pekerjaannya, mereka akan menghadirkan opportunity yang lebih luas pada kesuksesan perusahaan (Jufrizen, 2016). Witomo (2015) menjabarkan bahwa kepuasan kerja merefleksikan pandangan karyawan terhadap kariernya. Perusahaan akan mengalami kerugian ketika karyawan tidak puas dengan pekerjaan mereka karena dapat menyebabkan akibat buruk bagi perusahaan. Turnover adalah salah satu akibat buruk dari tidak puasnya seorang karyawan dengan pekerjaan mereka. Turnover menjadi isu yang krusial di dalam ruang lingkup perusahaan. Angka turnover karyawan harus dikendalikan oleh perusahaan agar perusahaan dapat menghemat anggaran, waktu, dan konsisten menjaga kelangsungan operasional perusahaan (Alamsyah, 2015).

Anshori dan Wangi (2017) mengartikan turnover sebagai hasrat seseorang untuk mengundurkan diri dari pekerjaannya (meninggalkan pekerjaan) dengan ikhlas sesuai dengan pilihan dirinya sendiri. Aspek-aspek yang diidentifikasi memengaruhi turnover intention karyawan salah satunya yaitu kepuasan kerja (Nafiudin, 2019). Secara umum, keinginan untuk meninggalkan pekerjaan dimiliki oleh karyawan yang merasa tidak puas (Pawesti dan Wikansari, 2016). Siregar (2015) berpendapat bahwa kepuasan kerja karyawan dalam suatu perusahaan selalu berbeda ditinjau dari kebutuhan setiap karyawan dengan ciri khas yang berbeda dalam kondisi yang berpengaruh pada kepuasan kerja karyawan tersebut.

Penelitian terdahulu yang relevan dengan pernyataan di atas dilakukan oleh Youcef, et al. (2016), Chalim (2018), Rismayanti, dkk (2018), Alam (2016), Ali, et al. (2018), dan Ibrar (2015) yang menyatakan bahwa kepuasan kerja berpengaruh negatif dan signifikan terhadap keinginan karyawan untuk keluar. Namun, Simone, et al. (2018) mengemukakan hasil penelitian yang kontras yakni mengungkapkan apabila job satisfaction memiliki pengaruh secara signifikan positif terhadap turnover intention.

Selain job satisfaction, organizational commitment juga merupakan prediktor yang akurat untuk menilai tingkat keinginan karyawan untuk keluar dari perusahaan (Mahendra, et al., 2017). Satwari, dkk. (2016) memaparkan bahwa keinginan untuk berhenti bekerja dikontrol kuat oleh organizational commitment. Organizational commitment adalah tindakan yang mencerminkan kesetiaan dan komitmen karyawan pada perusahaan di mana karyawan suatu perusahaan mengekspresikan rasa pedulinya terhadap perusahaan (Gumiwang, 2016). Loyalitas karyawan dan pencapaian misi, visi, tujuan, dan value perusahaan oleh karyawan adalah bentuk komitmen organisasional karyawan kepada perusahaan (Hkualizaman, et al., 2018).

Penelitian terdahulu yang membuktikan bahwa komitmen organisasional memiliki pengaruh terhadap keinginan untuk keluar secara signifikan negatif dibuktikan oleh Ali, et al. (2018), Chalim (2018), Indrayanti dan Riana (2018), Azeez dan Adeoye (2016), serta Anjani, dkk (2018). Berbeda dengan penelitian yan dilakukan oleh Ibrar (2015) menjelaskan tidak ada hubungan yang signifikan antara dua variabel yakni organizational commitment terhadap turnover intention.

Selain memengaruhi turnover intention, variabel komitmen organisasional juga bisa dipengaruhi oleh job satisfaction. Ali, et al. (2018), Chalim (2018), Indrayanti dan Riana (2018), Anjani, dkk (2018), serta Tarigan dan Ariani (2015) membuktikan bahwa job satisfaction memberikan pengaruh yang signifikan positif terhadap organizational commitment. Namun keadaan kontras yang dibuktikan oleh Köse (2017) yang menjelaskan tak adanya hubungan yang signifikan antara job satisfaction dan organizational commitmen.

Lokasi penelitian ini adalah PT Pancaputra Mitratama Mandiri yang didirikan pada tanggal 16 Juli 2004. PT Pancaputra Mitratama Mandiri adalah distributor resmi dari PT Shell Indonesia. Sesuai dengan hasil pengamatan yang ditelaah bahwa terdapat fenomena terkait turnover intention di perusahaan tersebut. Bersumber dari data Rekapitulasi Sumber Daya Manusia dari tahun 2015-2020 yang diperoleh dari Sistem Informasi PT Pancaputra Mitratama Mandiri membuktikan bahwa dalam tahun 2015 mengalami angka turnover yang lebih tinggi dibandingkan dengan pada tahun 2016 dan 2017. Tahun 2015 terdapat 6 orang karyawan yang melakukan turnover, pada 2016, terdapat 2 karyawan yang mengalami turnover, dan pada 2017, terdapat 3 karyawan yang memutuskan untuk 
melakukan turnover. Data tersebut juga menjelaskan bahwa tingkat turnover meningkat pada tahun 2019 jika dibanding pada tahun 2018. Yakni pada tahun 2018 hanya ada seorang karyawan saja yang memutuskan untuk mengundurkan diri (turnover), namun pada tahun 2019 terdapat lima karyawan yang memutuskan untuk mengundurkan diri (turnover).

Dari uraian kondisi terbaru perusahaan tersebut mengenai melonjaknya tingkat turnover pada 2019 dapat dikatakan bahwa PT Pancaputra Mitratama Mandiri sedang dalam permasalahan terkait kinerja dan produktivitas karyawan yang mengakibatkan turnover pada karyawan. Hal ini diduga karena beberapa faktor yaitu rasa puas akan pekerjaannya (job satisfaction) yang dimiliki karyawan belum juga terpenuhi. Hal ini didukung oleh hasil tanya jawab dengan salah satu karyawan di PT Pancaputra Mitratama Mandiri, menyatakan bahwa tingginya angka turnover pada tahun 2019 karena karyawan merasa tidak sanggup menjalankan tugasnya dan butuh tambahan karyawan tetapi atasan tidak menggubris hal tersebut. Selain itu, pernyataan seorang karyawan yang memiliki niat untuk mencari pekerjaan baru yakni karena alasan pribadi (ingin mendapatkan pekerjaan dengan posisi yang sama di tempat yang berbeda dengan peluang yang lebih besar secara berkepanjangan).

Namun di sisi lain, terdapat komitmen organisasi yang terjadi di PT Pancaputra Mitratama Mandiri. Dari hasil wawancara dengan beberapa karyawan yang berusia 26 - 52 tahun dengan masa kerja lebih dari 5 tahun, mereka menyatakan bahwa perusahaan memiliki arti besar bagi mereka, perusahaan begitu memperhatikan kesejahteraan karyawan baik kesejahteraan berupa materi maupun non materi. Karyawan merasa berkewajiban untuk merawat perusahaan dan membangun bersama-sama sekaligus ikut merasa memiliki perusahaan, sehingga perusahaan sangat layak untuk mendapatkan kesetiaan dari karyawan yang telah bekerja lebih dari 5 tahun. Kesetiaan karyawan ditunjukkan dengan keinginan mereka untuk tetap berada di perusahaan.

Penelitian ini bertujuan untuk menguji dan menganalisis bagaimana pengaruh job satisfaction terhadap turnover intention pada karyawan PT Pancaputra Mitratama Mandiri, menguji dan menganalisis bagaimana pengaruh job satisfaction terhadap organizational commitment pada karyawan PT

Pancaputra Mitratama Mandiri, menguji dan menganalisis bagaimana pengaruh organizational commitment terhadap turnover intention pada karyawan PT Pancaputra Mitratama Mandiri, serta menguji dan menganalisis bagaimana pengaruh job satisfaction terhadap turnover intention melalui organizational commitment pada karyawan PT Pancaputra Mitratama Mandiri.

\section{KAJIAN PUSTAKA DAN PENGEMBANGAN HIPOTESIS}

\section{Job Satisfaction}

Job satisfaction adalah di mana para karyawan menilai pekerjaan mereka dan menghasilkan perasaan yang memuaskan atau tidak memuaskan (Rahman, 2017). Menurut Youcef, et al. (2016) job satisfaction sebagai kombinasi antara kondisi psikologis, fisiologis, dan lingkungan yang menyebabkan seorang karyawan dengan jujur secara ikhlas mengatakan bahwa mereka puas dengan pekerjaannya. Badriyah (2015) berpendapat job satisfaction adalah perasaan seorang karyawan terhadap pekerjaan. Sejalan dengan itu, Hasibuan (2016) mengartikan job satisfaction sebagai kondisi emosi karyawan saat terjadinya pertemuan antara feedback yang diberikan pekerjaan dengan feedback yang diharapkan oleh karyawan. Feedback karyawan dalam hal ini yaitu berapa materiil maupun non materiil. Agar kontribusi, pengabdian, moral kerja, dan kedisiplinan karyawan meningkat, maka perusahaan harus membangun job satisfaction pada karyawan dengan sebaik mungkin.

Hardiansyah, et al. (2018) menjabarkan arti dari kepuasan kerja (job satisfaction) yakni sebagai suatu emosi positif tentang pekerjaan seseorang yang merupakan hasil dari sebuah evaluasi sikap individualitasnya. Kepuasan kerja, dalam pengertian umum, dianggap sebagai dampak positif dari pengalaman pekerja terhadapa lingkungan kerjanya dan perilaku positif yang dihasilkan dari pengalaman saat bekerja (Köse, 2017). Changgriawan (2017) menyatakan job satisfaction diukur melalui 5 indikator yakni, working condition, pay, promotion opportunity, bosses, dan relationship with co-workers. 
Gita Kusuma Dewi \& Budiono. Peran Mediasi Organizational Commitment pada Pengaruh Job Satisfaction terhadap Turnover Intention pada Karyawan PT Pancaputra Mitratama Mandiri.

\section{Organizational Commitment}

Damri, dkk. (2017) mendefinisikan bahwa organizational commitment adalah sebagai hubungan psikologis seorang karyawan terhadap perusahaan meliputi kontribusi karyawan, loyalitas, dan kepercayaan dari karyawan terhadap value perusahaan. Organizational Commitment adalah tingkat di mana seorang karyawan merasakan kesetiaan kepada organisasi tertentu (Köse, 2017). Oktaviani (2018) memaparkan bahwa komitmen organisasi ialah tingkatan sejauh mana seorang individu atau karyawan percaya serta dapat menerima tujuan dari organisasi dan masih memiliki keinginan untuk tetap tinggal bersama organisasi tersebut. Kemudian dengan adanya komitmen dari karyawan, maka akan menciptakan loyalitas terhadap perusahaan dan keinginan untuk dapat mencapai tujuan perusahaan dengan baik.

Yulianti (2015) menyatakan bahwa organizational commitment adalah pendekatan sikap memusatkan pada cara di mana individu memikirkan hubungannya dengan organisasi, dengan cara menyelaraskan antara visi, misi, dan tujuannya dengan organisasi. Organizational commitment adalah bentuk pengaktualan psikologis yang mengkarakteristikkan ikatan antara seseorang dengan organisasi serta memiliki pemikiran pada pertimbangan akan tetap meneruskan ataupun tak meneruskan posisinya di dalam organisasi (Salam dan Sahrah, 2019). Cerminan sikap karyawan yang mempresentasikan kesetiaan dan komitmen karyawan pada perusahaan dan menjadi proses berkelanjutan dengan menunjukkan perhatiannya terhadap perusahaan dan keberhasilan perusahaan adalah penjelasan dari organizational commitment (Sambung, 2016). Haris (2017) menjabarkan pengertian organizational commitment sebagai hasrat untuk selalu berupaya keras menjadi karyawan yang diharapkan dan diinginkan oleh perusahaan, berkeinginan kuat untuk memerankan keanggotaannya di dalam sistem, berambisi untuk tetap berupaya sesuai keinginan organisasi, berkeyakinan serta menanamkan rasa kepercayaan akan value maupun tujuan organisasi.

Sedangkan Yulianti (2015) menyatakan terdapat 3 indikator dari komitmen organisasi, yakni sebagai berikut. (1) Komitmen afektif, yakni karyawan yang mempunyai komitmen afektif yang kuat akan berusaha untuk tetap berada di dalam perusahaan dan menjadi anggota perusahaan karena mereka masih mengingikan hal tersebut (want to). (2) Komitmen Kontinu, yakni dimana sebuah komitmen yang didasarkan adanya kesadaran biaya yang memiliki hubungan dengan resiko yang harus mereka tanggung jika meninggalkan perusahaan. Karyawan yang memiliki komitmen berkelanjutan kuat akan tetap berada di dalam organisasi karena mereka membutuhkannya (need to). (3) Komitmen Normatif, menjelaskan bahwa jika seseorang karyawan memiliki komitmen normatif yang tinggi, maka mereka akan memutuskan untuk berusaha tinggal dengan perusahaan karena mereka harus melakukan hal tersebut (ought to).

\section{Turnover Intention}

Suifan, et al. (2016) mendefinisikan turnover intention sebagai kemauan karyawan menarik diri dari pekerjaannya ke perusahaan yang lain sesuai dengan pilihan dirinya sendiri. Arfian dan Anindita (2017) berpendapat turnover intention yakni hasrat yang muncul untuk berhenti bekerja dari perusahaan. Turnover intention adalah suatu proses di mana karyawan mengundurkan diri dari posisi pekerjaannya saat ini dan kelak diambil alih oleh orang lain (Sa'diyah, dkk., 2017).

Turnover dapat berupa pengunduran diri, perpindahan keluar dari suatu perusahaan, pemberhentian atau kematian anggota organisasi atau perusahaan (Widyantara dan Ardana, 2015). Perdana (2015), menjelaskan bahwa penarikan diri seseorang keluar dari suatu organisasi (turnover) dapat diputuskan secara sukarela (voluntary turnover) maupun secara tidak sukarela (involuntary turnover). Voluntary turnover atau quit merupakan keputusan karyawan untuk meninggalkan organisasi secara sukarela yang disebabkan oleh beberapa faktor yang menarik pada saat ini, dan tersedianya alternatif pekerjaan lain. Sebaliknya, involuntary turnover atau pemecatan menggambarkan keputusan pemberi kerja untuk menghentikan hubungan kerja dan bersifat uncontrollable bagi karyawan yang mengalaminya.

Voluntary turnover dibedakan berdasarkan sifat, yakni dapat dihindari (avoidable voluntary turnover) dan tidak dapat dihindari (unavoidable voluntary turnover). Avoidable voluntary turnover muncul karena adanya alasan upah yang lebih baik, kondisi kerja yang lebih baik, masalah dengan pimpinan, 
atau alternatif tempat kerja lain yang lebih baik. Perdana (2015) menyatakan bahwa unavoidable voluntary turnover terjadi karena pindah ke kota lain mengikuti pasangannya, perubahan karier individu, tinggal di rumah menjaga anak-anak dan karena kehamilan.

Wong and Wong (2017) menjelaskan terdapat tiga indikator pengukuran turnover intention yang terdiri atas: 1) a tendency to think of quitting, pemikiran untuk keluar, yakni pemikiran untuk keluar dari organisasi atau tetap berada dan tinggal di dalam lingkungan organisasi. 2) a possibility to seek for alternative jobs in a near time elsewhere, kemungkinan mencari pekerjaan baru, kemungkinan individu akan mencari pekerjaan lain di waktuyang akan datang. 3) being active to seek for alternative jobs elsewhere, secara aktif mencari pekerjaan, yang berarti individu akan secara aktif mencari pekerjaan di tahun depan.

\section{Hubungan antar Variabel}

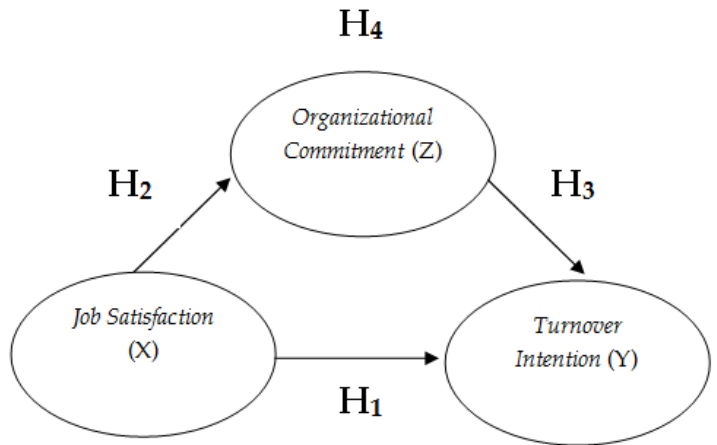

\section{Gambar 1. KERANGKA KONSEPTUAL}

Hubungan antar variabel dapat diamati dalam Gambar 1. Menurut Pawesti dan Wikansari (2016), cara mengukur karyawan yang ingin keluar dari perusahaan dengan akurat yaitu dilihat dari kepuasan seseorang terhadap pekerjaannya. Job satisfaction memiliki peran untuk mengantisipasi perilaku keinginan untuk keluar secara nyata. Dalam implementasinya, job satisfaction sangat memengaruhi turnover intention pada suatu perusahaan. Ketidakpuasan kerja akan memengaruhi angka pergantian atau perpindahan karyawan yang tinggi. Mufidah (2016) menjelaskan keinginan karyawan untuk keluar dari perusahaannya dipengaruhi secara langsung oleh kepuasan kerja.

H1: Diduga job satisfaction berpengaruh signifikan negatif terhadap turnover intention.

Kepuasan kerja merupakan prasyarat penting bagi terwujudnya sebuah lingkungan organisasi yang masif (Kuswibowo, 2017). Karyawan yang memiliki motivasi kerja dan mudah untuk memotivasi diri sendiri dalam pekerjaannya lebih condong untuk memiliki kepuasan kerja yang baik. Dari eksplanasi tersebut, dapat dijelaskan bahwa semakin tinggi tingkat job satisfcation, semakin meningkat organizational commitment pada karyawan (Akbar, dkk., 2016). Mufidah (2016) juga berpendapat bahwa job saisfaction berpengaruh secara langsung pada komitmen awal sebelum memasuki perusahaan. Hal ini menjelaskan bahwa apabila organizational commitment pada karyawan meningkat sehingga dikatakan berbanding lurus di mana puasnya karyawan terhadap pekerjaannya juga tentu bertambah meningkat. Tingginya organizational commitment terbentuk dari job satisfaction milik karyawan yang sangat baik di mana kecenderungan seorang karyawan agar tetap mempertahankan pekerjaannya secara kontinu dan menetap di perusahaannya.

H2: Diduga job satisfaction berpengaruh signifikan positif terhadap organizational commitment.

Selaras dengan job satisfaction, organizational commitment juga berpengaruh negatif terhadap keinginan karyawan untuk keluar dari perusahaan. Wonowijoyo dan Tanoto (2018) menjelaskan bahwa rendahnya tingkat absensi karyawan adalah pengaruh dari tingginya tingkat komitmen karyawan. Dengan demikian menunjukkan bahwasanya keinginan karyawan untuk mengundurkan diri dari perusahaan menurun. Lain daripada itu, karyawan yang konsisten memperlihatkan komitmen 
Gita Kusuma Dewi \& Budiono. Peran Mediasi Organizational Commitment pada Pengaruh Job Satisfaction terhadap Turnover Intention pada Karyawan PT Pancaputra Mitratama Mandiri.

organisasionalnya terhadap perusahaan akan membuat dirinya lebih condong untuk mengambil tindakan ekstra dan usaha lebih di luar kualifikasi biasa agar bisa membentengi dirinya untuk tidak ikut serta dalam perilaku kontraproduktif, salah satu diantaranya yakni keinginan untuk mencari pekerjaan baru (Suifan, et al., 2016)

H3: Diduga organizational commitment berpengaruh signifikan negatif terhadap turnover intention.

Indrayanti dan Riana (2018) mendapati variabel organizational commitment mampu memediasi pengaruh job satisfaction terhadap turnover intention. Wahyuni, dkk., (2014) berpendapat job satisfaction berpengaruh positif pada komitmen awal sebelum memasuki perusahaan. Hal ini berbanding lurus apabila tingkat job satisfaction karyawan tinggi, maka tingkat organizational commitment yang dimiliki akan meningkat. Karyawan dengan kepuasan kerja yang tinggi dapat dinyatakan bahwa memiliki komitment organisasional yang tinggi dan akan cenderung untuk tetap mempertahankan pekerjaannya dalam perusahaan dan secara berkelanjutan dan tidak meninggalkan perusahaan serta pekerjaannya, sehingga angka turnover intention akan mengalami penurunan.

H4: Diduga organizational commitment memediasi pengaruh job satisfaction terhadap turnover intention.

\section{METODE PENELITIAN}

Penelitian ini menerapkan metode kuantitatif. Metode observasi, wawancara lalu dilanjutkan dengan penyebaran kuesioner adalah cara yang dilakukan guna pengumpulan data dalam penelitian ini. Skala Likert 1-5 adalah metode perhitungan dalam penelitian ini. Lokasi penelitian ini yakni PT Pancaputra Mitratama Mandiri, yang beralamat di J1. Kupang Indah I No.11, Sonokwijenan, Kota Surabaya, Jawa Timur. Sampel jenuh adalah teknik pengambilan sampel yang digunakan dengan jumlah seluruh karyawan PT Pancaputra Mitratama Mandiri sebagai responden yakni sebanyak 32 orang. Hasil pengelolaan data dalam penelitian ini didukung oleh software di komputer yakni program aplikasi smart PLS 3.0 dan dianalisis menggunakan Structural Equation Modelling (SEM) dengan analysis method yakni partial least square (PLS).

Pengukuran job satisfaction menggunakan indikator yang merujuk pada Changgriawan (2017), yaitu: working condition, pay, promotion opportunity, bosses, dan relationship with co-workers. Kemudian, pengukuran turnover intention menggunakan indikator yang merujuk pada Wong dan Wong (2017), yaitu: a tendency to think of quitting, a possibility to seek for alternative jobs in a near time elsewhere, dan being active to seek for alternative jobs elsewhere. Selanjutnya, pengukuran organizational commitment merujuk pada indikator Yulianti (2015), yaitu komitmen afektif, komitmen kontinu, dan komitmen normatif.

\section{HASIL DAN PEMBAHASAN}

\section{Deskripsi Responden}

Jumlah responden yang mengembalikan kuisioner adalah 32 orang. Berikut adalah deskripsi dan keterangan berdasarkan karakteristik responden menurut jenis kelamin, umur, jenjang pendidikan, status, dan masa kerja. Pada penelitian ini dari jumlah sampel keseluruhan yakni 32 responden, pria berjumlah 22 karyawan $(68,8 \%)$ dan wanita berjumlah 10 karyawan $(31,2 \%)$. Karyawan yang berumur antara $\leq 30$ tahun berjumlah 12 karyawan (37,5\%), lalu yang berumur antara 31-41 tahun berjumlah 15 karyawan (46,9\%), sementara itu yang berumur antara 42-51 tahun berjumlah 4 karyawan (12,5\%), dan yang berumur $>52$ tahun berjumlah 1 karyawan $(3,1 \%)$. Karyawan dengan jenjang pendidikan SMP berjumlah 2 orang $(6,3 \%)$, karyawan dengan jenjang pendidikan SMA/SMK berjumlah 13 orang $(40,6 \%)$, karyawan dengan jenjang pendidikan D3 berjumlah 5 orang $(15,6 \%)$, karyawan dengan jenjang jenjang pendidikan S1/D4 berjumlah 11 orang $(34,4 \%)$, dan karyawan jenjang pendidikan S2 berjumlah 1 orang $(3,1 \%)$. Selanjutnya, untuk karyawan dengan menikah berjumlah 28 orang $(87,5)$, dan dengan status belum menikah sebanyak 4 orang (12,5\%). Selanjutnya, untuk karyawan dengan masa kerja selama rentang waktu $\leq 5$ tahun berjumlah 25 karyawan $(78,1 \%)$, kemudian karyawan yang 
telah bekerja selama rentang waktu antara 6 - 10 tahun yakni 5 karyawan (15,6\%), selanjutnya karyawan yang telah bekerja selama $>11$ tahun sebanyak 1 karyawan $(3,1 \%)$.

Penelitian ini menggunakan three box method untuk penilaian rata-rata jawaban responden di mana angka paling rendah adalah 1 dan paling tinggi adalah 5. Adapun penjelasannya rata-rata penilaian indikator variabel job satisfaction yaitu sebesar 3,59 untuk indikator working condition, sebesar 3,71 untuk indikator pay, sebesar 3,81 untuk indikator promotion opportunity, sebesar 3,87 untuk indikator bosses, dan sebesar 3,59 untuk indikator relationship with co-workers dengan rata-rata variabel job satisfaction sebesar 3,72 yang tergolong dalam kategori tinggi. Nilai rata-rata indikator dari organizational commitment yakni sebesar 3,72 untuk komitmen afektif, sebesar 3,97 untuk komitmen kontinu, dan sebesar 3,81 untuk komitmen normatif dengan rata-rata variabel organizational commitment sebesar 3,83 yang tergolong kategori tinggi. Adapun indikator turnover intention di antaranya a tendency to think of quitting sebesar 1,88, a possibility to seek for alternative jobs in a near time elsewhere sebesar 2,09, dan being active to seek for alternative jobs elsewhere sebesar 1,84 dengan rata-rata variabel turnover intention sebesar 1,94 yang tergolong kategori rendah.

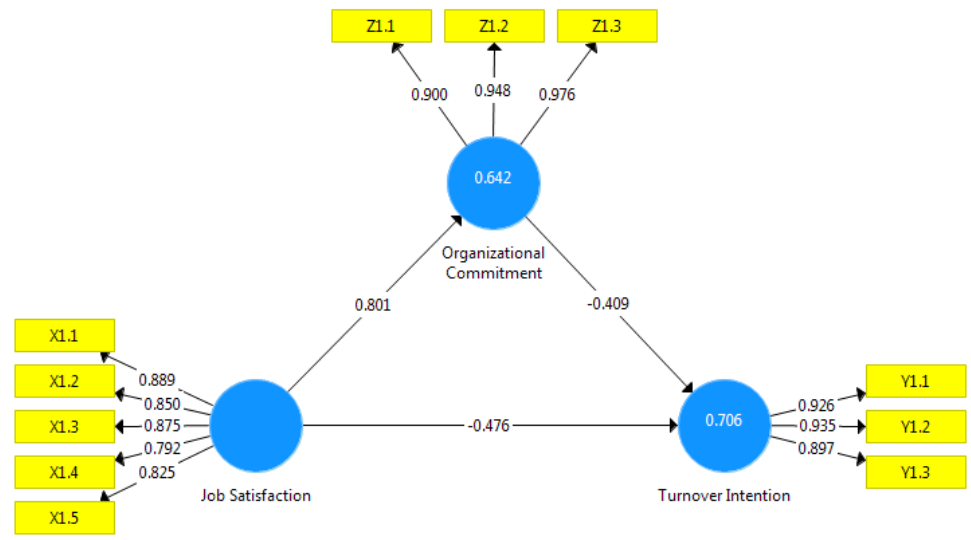

Sumber: Smart PLS 3.0 (2020, data diolah)

Gambar 2. UJI MEASUREMENT MODEL

Gambar 2 memperlihatkan bahwa outer loadings setiap indikator memiliki angka yang melebihi angka 0,50 . Dengan demikian membuktikan bahwa indikator setiap variabel dinyatakan valid. Hal ini menjelaskan bahwa penelitian ini menggunakan variabel dengan convergent validity yang baik.

Berdasarkan Tabel 1, composite reliability pada penelitian ini menggunakan variabel sebesar melebihi angka 0,70. Ditinjau dari data, model variabel telah diuji memiliki reliabilitas yang baik atau telah memenuhi composite reliability. Tabel 1 juga memaparkan bahwasanya angka cronbach's alpha milik seluruh konstruk model sebesar melebihi angka 0,70 yang berarti seluruhnya memiliki reliabilitas yang kuat atau telah mencukupi cronbach's alpha.

Berdasarkan Tabel 3, pengaruh job satisfaction terhadap turnover intention memiliki nilai $t$-statistics sebesar 2,662 > 1,96. Hal tersebut menjelaskan pengaruh signifikansi antara variabel job satisfaction dengan turnover intention. Sementara itu angka koefisien estimate yakni $-0,476$ yang bertanda negatif yang memiliki makna apabila semakin baik job satisfaction maka turnover intention akan menurun, begitupun sebaliknya.

Selanjutnya, pengaruh job satisfaction terhadap organizational commitment dengan angka $t$-statistics sejumlah 10,882 > 1,96. Hal tersebut menjelaskan antara variabel job satisfaction dan organizational commitment berpengaruuh secara signifikan. Sementara itu angka koefisien estimate yaitu 0,801 dan bertanda positif yang bermakna semakin baik job satisfaction dengan demikian akan bertambah baik pula organizational commitment, begitupun kebalikannya. 
Gita Kusuma Dewi \& Budiono. Peran Mediasi Organizational Commitment pada Pengaruh Job Satisfaction terhadap Turnover Intention pada Karyawan PT Pancaputra Mitratama Mandiri.

Tabel 1.

COMPOSITE RELIABILITY DAN CRONBACH'S ALPHA

\begin{tabular}{lcc}
\hline \multicolumn{1}{c}{ Variabel } & Composite Reliability & Cronbach's Alpha \\
\hline Job Satisfaction & 0,927 & 0,901 \\
Turnover Intention & 0,959 & 0,935 \\
Organizational Commitment & 0,943 & 0,909 \\
\hline Sum
\end{tabular}

Sumber: Smart PLS 3.0 (2020, data diolah)

Tabel 2.

NILAI R-SQUARE MODEL

\begin{tabular}{lc}
\hline \multicolumn{1}{c}{ Variabel } & R-Square \\
\hline Organizational Commitment & 0,642 \\
Turnover Intention & 0,706 \\
\hline Sumber: Smart PLS 3.0 (2020, data
\end{tabular}

Sumber: Smart PLS 3.0 (2020, data diolah)

Tabel 3.

PENGARUH LANGSUNG DAN TIDAK LANGSUNG

\begin{tabular}{lccc}
\hline \multicolumn{1}{c}{ Variabel } & Original Sample & T-Statitstics & Keterangan \\
\hline $\begin{array}{l}\text { Job Satisfaction } \rightarrow \text { Turnover Intention } \\
\text { Job Satisfaction } \rightarrow \text { Organizational }\end{array}$ & $-0,476$ & 2,662 & Hipotesis Diterima \\
$\begin{array}{l}\text { Commitment } \\
\text { Organizational Commitment } \rightarrow\end{array}$ & 0,801 & 10,882 & Hipotesis Diterima \\
$\begin{array}{l}\text { Turnover Intention } \\
\text { Job Satisfaction } \rightarrow \text { Turnover Intention }\end{array}$ & $-0,409$ & 2,187 & Hipotesis Diterima \\
$\rightarrow$ Organizational Commitment & $-0,328$ & 2,203 & Hipotesis Diterima \\
\hline S
\end{tabular}

Sumber: Smart PLS 3.0 (2020, data diolah)

Nlai $t$-statistics pengaruh organizational commitment terhadap turnover intention sebesar 2,187 > 1,96. Data tersebut menjelaskan bahwa terdapat signifikansi pengaruh antara variabel organizational commitment dan turnover intention. Sementara itu koefisien estimate sebesar -0,409 dan bertanda negatif yang memilik makna di mana semakin baik tingkat organizational commitment sehingga turnover intention akan menurun, begitu pula dengan kebalikannya.

\section{Pengaruh Job Satisfaction terhadap Turnover Intention}

Hasil analisis membuktikan job satisfaction berpengaruh signifikan negatif terhadap turnover intention. Hasil ini dapat diartikan bahwa semakin tinggi job satisfaction yang dimiliki karyawan PT Pancaputra Mitratama Mandiri, maka akan semakin rendah pula tingkat turnover intention PT Pancaputra Mitratama Mandiri.

Beberapa penelitian terdahulu yang menguatkan hasil peneliatin ini dihasilkan Ali, et al. (2018), Youcef, et al. (2016), Rismayanti, dkk. (2018), Alam (2016), Indrayanti dan Riana (2018), Anjani, dkk (2018), Chan, et al. (2016), dan Chalim (2018) yang menuturkan adanya hubungan signifikan dan negatif antara job satisfaction terhada turnover intention. Hal ini membuktikan pandangan sistematis adanya hubungan negatif antara job satisfaction dan turnover intention. Sama halnya dengan pernyataan Pawesti dan Wikansari (2016), bahwa variabel psikologis paling sering dipakai untuk mengamati perasaan puas seseorang terhadap pekerjaannya dalam pengaruh antar job satisfaction terhadap turnover intention.

Hal tersebut didukung dengan hasil deskriptif jawaban responden untuk variabel job satisfaction yang terjadi pada karyawan PT Pancaputra Mitratama Mandiri termasuk dalam kategori tinggi. Kemudian hasil statistik nilai rata-rata untuk variabel turnover intention termasuk dalam kategori rendah. Hal ini menunjukkan semakin tinggi kepuasan kerja yang dirasakan oleh karyawan PT Pancaputra Mitratama 
Mandiri maka akan menyebabkan semakin rendah keinginan karyawan untuk berhenti dari pekerjaannya.

\section{Pengaruh Job Satisfaction terhadap Organizational Commitment}

Hasil analisis membuktikan bahwa terdapat pengaruh signifikan positif job satisfaction terhadap organizational commitment pada PT Pancaputra Mitratama Mandiri. Hasil ini dapat diartikan bahwa semakin tinggi tingkat job satisfaction yang dimiliki karyawan PT Pancaputra Mitratama Mandiri, maka akan semakin tinggi pula tingkat organizational commitment pada karyawan PT Pancaputra Mitratama Mandiri.

Penelitian terdahulu yang relevan memperkuat hasil penelitian ini yakni hasil dari Youcef, et al. (2016), Ali, et al. (2018), Chalim (2018), Indrayanti dan Riana (2018), Anjani, dkk (2018), serta Tarigan dan Ariani (2015) yang membuktikan bahwasanya organizational commitment dapat dipengaruhi oleh job satisfaction secara positif dan signifikan.

Hal tersebut didukung dengan hasil deskriptif jawaban responden untuk variabel job satisfaction yang terjadi pada karyawan PT Pancaputra Mitratama Mandiri yaitu dalam kategori tinggi. Begitu juga dengan hasil statistik nilai rata-rata untuk variabel organizational commitment termasuk dalam kategori tinggi. Hal ini membuktikan pandangan sistematis mengenai kepuasan kerja dan komitmen organisasai yang ada. Akbar, dkk. (2016) menjelaskan bahwa kepuasan kerja yang lebih besar didapatkan oleh anggota dengan komitmen yang tinggi pada organisasinya serta anggota yang mempunyai job satsifaction yang baik akan mempunyai komitmen organisasional dengan tingkatan baik pada perusahaannya. Komitmen organisasi dapat terwujud dari dorongan kepuasan kerja karyawan.

Penjelasan di atas diperkuat hasil wawancara dengan karyawan PT Pancaputra Mitratama Mandiri yang tak terstruktur di mana sebagian dari karyawan menuturkan bahwa atasan mereka di perusahaan sangat menghargai dan mengakui peran serta karyawan di dalam perusahaan, penghargaan oleh perusahaan diwujudkan dalam bentuk memberikan pengharaagaan berupa insentif. Sikap positif yang muncul dari hubungan karyawan dengan perusahaan tercipta dari kepuasan kerja yang menumbuhkan komitmen dari karyawan PT Pancaputra Mitratama Mandiri.

\section{Pengaruh Organizational Commitment terhadap Turnover Intention}

Bersumber pada hasil pengujian hipotesis, penelitian ini mendapati adanya pengaruh signifikan negatif antara organizational commitment terhadap turnover intention pada PT Pancaputra Mitratama Mandiri. Semakin tinggi organizational commitment pada karyawan PT Pancaputra Mitratama Mandiri maka semakin menurunkan tingkat turnover intention.

Hasil penelitian yang relevan oleh Fahrizal dan Utama (2017), Ali, et al. (2018), Chalim (2018), Indrayanti dan Riana (2018), Azeez dan Adeoye (2016), Tarigan dan Ariani (2015), Anjani, dkk (2018), Bhatti, et al. (2016), serta Setiyanti dan Hidayati (2017) menguatkan hasil uji hipotesis yakni organizational commitment berpengaruh secara signifikan negatif turnover intention.

Didukung oleh hasil penilaian responden variabel organizational commitment pada karyawan PT Pancaputra Mitratama Mandiri tergolong kategori tinggi. Berbeda halnya dengan hasil statistik nilai rata-rata variabel turnover intention tergolong kelompok rendah. Hal ini membuktikan hasil di mana semakin tinggi tingkat organizational commitment, sehingga memengaruhi tingkat turnover intention yang rendah yang ada pada PT Pancaputra Mitratama Mandiri.

\section{Pengaruh Job Satisfaction terhadap Turnover Intention melalui Organizational Commitment}

Penelitian ini terdiri dari variabel bebas, variabel terikat, dan variabel intervening (penghubung). Variabel bebas yang digunakan dalam penelitian ini adalah job satisfaction. Sedangkan variabel terikat dalam penelitian ini adalah turnover intention, dan variabel penghubung yaitu organizational commitment. 
Gita Kusuma Dewi \& Budiono. Peran Mediasi Organizational Commitment pada Pengaruh Job Satisfaction terhadap Turnover Intention pada Karyawan PT Pancaputra Mitratama Mandiri.

Berdasarkan hasil analisis pengaruh tidak langsung job satisfaction terhadap turnover intention melalui organizational commitment adalah signifikan. Begitu juga dengan pengaruh langsung job satisfaction terhadap turnover intention juga signifikan. Maka dapat diartikan bahwa organizational commitment memiliki peranan sebagai intervening atau memediasi pengaruh antara job satisfaction terhadap turnover intention.

Dengan demikian menguatkan penelitian yang dilakukan Mufidah (2016) bahwa job satisfaction berpengaruh secara langsung pada komitmen awal sebelum karyawan memasuki perusahaan. Maka dengan ini menerangkan tingginya job satisfaction karyawan akan meningkatkan organizational commitment karyawan. Karyawan dengan kepuasan kerja yang baik dapat diintrepretasikan bahwasanya karyawan termasuk memiliki komitmen organisasional yang baik dan lebih condong mempertahankan posisinya untuk tetap dan tidak meninggalkan perusahaan.

Apabila dihubungkan dengan penelitian yang dilaksanakan di PT Pancaputra Mitratama Mandiri, dengan didukung melalui kumpulan dari hasil wawancara dengan karyawan PT Pancaputra Mitratama Mandiri bahwa semakin bertahap karyawan telah mempunyai kepuasan dalam bekerja, baik dalam hal jenis pekerjaan itu sendiri, upah yang diberikan oleh perusahaan, dukungan dari atasan dan rekan kerja yang berada di perusahaan, karyawan enggan meninggalkan perusahaan karena sudah merasa nyaman. Hal ini dapat menginformasikan bahwa komitmen organisasi karyawan terhadap pekerjaan yang dirasakan memiliki pengaruh signifikan positif pada kepuasan kerja setiap karyawan.

\section{KESIMPULAN}

Dari pembahasan yang telah dijabarkan di atas, hasil penelitian ini yaitu: (1) job satisfaction berpengaruh signifikan negatif terhadap turnover intention; (2) job satisfaction berpengaruh signifikan positif terhadap organizational commitment; (3) organizational commitment berpengaruh signifikan negatif terhadap turnover intention;(4) job satisfaction berpengaruh signifikan negatif terhadap turnover intention melalui organizational commitment.

Kemudian penelitian ini memberikan beberapa saran praktis yang bersumber dari analisis, pengamatan, serta hasil wawancara yakni penelitian ini menyarankan untuk mempertahankan dan terus memperbaiki sistem pengelolaan personalia agar karyawan merasa nyaman saat melakukan pekerjaannya, serta peningkatan fasilitas yang menunjang kinerja karyawan dengan mengadakan alat transportasi yang memadai dan juga kebutuhan karyawan guna menunjang melakukan daily report, weekly report, dan montly report seperti personal computer, karena selama ini karyawan masih menggunakan laptop miliknya sendiri dan sesuai dengan wawancara dengan beberapa karyawan, hal ini cukup memberatkan karyawan.

Untuk itu, perusahaan dapat mengagendakan acara gathering family, atau outbond secara terstruktur. Saran tersebut akan meningkatkan komitmen organisasional pada karyawan di dalam perusahaan yang diikuti oleh bangkitnya semangat karyawan dengan rekan-rekannya untuk terus meningkatkan performanya dan juga kekompakan antar karyawan sehinga merasakan kepuasan terhadap pekerjaannya serta dapat meningkatnya kinerja karyawan. Penelitian selanjutnya dapat melibatkan variabel lainnya yang juga dapat memengaruhi tingkat turnover intention pada PT Pancaputra Mitratama Mandiri yaitu motivasi kerja atau work life balance.

\section{DAFTAR PUSTAKA}

Akbar, F. H., Hamid, D., \& Djudi, M. (2016). Pengaruh Kepuasan Kerja terhadap Komitmen Organisasional dan Kinerja Karyawan (Studi pada Karyawan Tetap Pg Kebon Agung Malang). Jurnal Administrasi Bisnis S1 Universitas Brawijaya, 38(2), 79-88.

Alamsyah, V. D. (2015). The Effect of Job Satisfaction on Organizational Commitment and Impact on Employee Turnover Intention at PT. Primasindo Makmur Kencana. 151, 10-17. Https://Doi.Org/10.1145/3132847.3132886 
Anshori, A. K., \& Wangi, E. N. (2017). Pengaruh Percieved Organizational Support dan Komitmen Organisasi terhadap Intensi Turnover. Prosiding Psikologi, 3(2), 1069-1074.

Arfian, M. H., \& Anindita, R. (2017). Determinants of Turnover Intention in Information Technology Workers. International Journal of Economics, Commerce and Management United Kingdom, $V(4), 584-598$. Retrieved from http://ijecm.co.uk/

Badriyah, M. (2015). Manajemen Sumber Daya Manusia. Bandung: CV Pustaka Setia.

Bayraktar, O., \& Şencan, H. (2017). Employees’ Approaches to Human Resources from the AssetResource Concepts Perspective. International Journal of Business and Social Science, 8(9), 116127. Retrieved from www.ijbssnet.com

Changgriawan, G. S. (2017). Pengaruh kepuasan kerja dan motivasi kerja terhadap kinerja karyawan di one way production. 5(3).

Damri, Z., ' M., \& ' H. (2017). Pengaruh Komitmen Organisasi, Kepuasan Kerja, dan Kepemimpinan terhadap Disiplin Kerja Pegawai Biro Administrasi Pemerintahan Umum Provinsi Riau. Jurnal Online Mahasiswa Fakultas Ekonomi Universitas Riau, 4(1), 656-666.

Diputra Y., I., \& Mujiati, N. (2016). Pengaruh Kompensasi, Kepemimpinan dan Lingkungan Kerja terhadap Kinerja Karyawan pada Hotel Griya Santrian. E-Jurnal Manajemen Universitas Udayana, 5(4), 2369-2395.

Gumiwang, A. S. (2016). Pengaruh Budaya Organisasi terhadap Kepuasan Kerja melalui Komitmen Organisasi sebagai Variabel Mediasi pada Shared Services Departement Head Di PT. Angkasa Pura I (Persero) Kantor Cabang Bandar Udara Internasional Juanda Surabaya. Jurnal Ilmu Manajemen (JIM), 4(2).

Hardiansyah, A. T., Amelia, A., \& Santika, M. (2018). Kepuasan Kerja sebagai Faktor Terbentuknya Sikap Kerja Pegawai Negeri Sipil Kantor Kecamatan Klampis, Bangkalan Arisandi Tri Hardiansyah, Aisyah Amelia, Mila Santika Universitas Trunojoyo Madura. Kompetensi, 12(2), 167-187.

Haris, H. (2017). Pengaruh Kepuasan Kerja dan Komitmen Organisasi terhadap Kualitas Layanan di PT. Asuransi Jasindo (Persero) Kantor Cabang Korporasi dan Ritel Bandung. Jurnal Manajemen Dayasaing, 19(2), 135-151. Retrieved from http://journals.ums.ac.id/index.php/dayasaing/article/view/5513

Hasibuan, S. P. M. (n.d.). Manajemen Sumber Daya Manusia (Edisi Revi). Jakarta: Bumi Aksara.

Hkualizaman, T., Hamidah, H., \& Handaru, A. W. (2018). Investigating Organizational Culture among Civil Servants Organizational Commitment. Journal of Business and Behavioural Entrepreneurship, 2(2), 68-74. https://doi.org/10.21009/jobbe.002.2.03

Indrayanti, D. P. \& Riana, I. G. (2018). Pengaruh Kepuasan Kerja terhadap Turnover Intention melalui Mediasi Komitmen Organisasional pada PT. Ciomas Adisatwa di Denpasar. International Journal Of Management And Business Research, 6(2), 269-278. Https://Doi.Org/10.1108/Ijm01-2014-0005

Jufrizen. (2016). Efek Mediasi Kepuasan Kerja pada Pengaruh Kompensasi terhadap Kinerja Karyawan. Jurnal Ekonomi, Vol 17, No, Hal 1-18.

Köse, S. D., \& Köse, T. (2017). The Effect of Job Satisfaction on Organizational Commitment of Healthcare Personnel. IOSR Journal of Business and Management, 19(01), 54-59. 
Gita Kusuma Dewi \& Budiono. Peran Mediasi Organizational Commitment pada Pengaruh Job Satisfaction terhadap Turnover Intention pada Karyawan PT Pancaputra Mitratama Mandiri.

https://doi.org/10.9790/487x-1901025459

Kuswibowo, C. (2017). Kuswibowo: Hubungan Antara Kepuasan Kerja dan Komitmen Organisasi... $3(03), 1-8$.

Lestari, S. (2015). Pengelolaan Diversitas Karyawan dalam Membangun Keunggulan Kompetitif. Jurnal Fokus Bisnis, 14(01), 1-7.

Mahendra, I. K. G., Sudibya, I. G. A., \& Dewi, I. G. A. M. (2017). Pengaruh Kepuasan Kerja terhadap Turnover Intention Agen PT Prudential Indonesia Life Assurance Denpasar Abstract: The Role Of Organization Commitment To Mediate Effect Of Work Satisfaction. 22(2), 122-133.

Mufidah, L. (2016). Pengaruh Job Satisfaction terhadap Turnover Intention dengan Continuance Commitment sebagai Variabel Intervening Pada Karyawan EF Sinergy Consultant. Fakultas Ekonomi Dan Bisnis > Manajemen. Retrieved From Http://Repository.Unair.Ac.Id/Id/Eprint/53045

Nafiudin, N. (2019). Analisis Turnover Intention Karyawan Generasi Y di Provinsi Banten serta Faktor yang Memengaruhinya. Jurnal Penelitan Ekonomi Dan Bisnis, 2(1), 1-9. Https://Doi.Org/10.33633/Jpeb.V2i1.2230

Nanulaitta, D. T. (2018). Pengaruh Kompensasi dan Lingkungan Kerja terhadap Kinerja Karyawan pada KSU. Amboina Mekar di Kota Ambon. Jurnal Minds: Manajemen Ide Dan Inspirasi, 5(2), 203. Https://Doi.Org/10.24252/Minds.V5i2.6211

Oktaviani, H. (2018). Pengaruh Work Life Balance dan Perceived Organizational Support terhadap Turnover Intention melalui Organizational Commitment sebagai Variabel Intervening pada PT Berlian Jasa Terminal Indonesia. Jurnal Ilmu Manajemen (Jim), 6(3), 58-72.

Pawesti, R., \& Wikansari, R. (2016). Pengaruh Kepuasan Kerja terhadap Prestasi. Jurnal Ecopsy, 3(2), 49-67. Https://Doi.Org/10.20527/Ecopsy.V3i2.2649

Perdana, N. A. (2015). Pengaruh Kepuasan Kerja dan Komitmen Organisasi terhadap Turnover Intention pada Karyawan PT. Ganda Buanindo Kuantan Singingi Hilir. Faculty Of Econommic Riau University, Pekanbaru,Indonesia, 2(1), 1-18.

Rahman, M. (2017). Ilmu Administrasi. Sah Media.

Sa'diyah, H., Irawati, S. A., \& Faidal. (2017). Pengaruh Employee Retention dan Turnover Intention terhadap Kinerja Karyawan melalui Kepuasan Kerja Pada Kospin Jasa Cabang Jawa Timur. 11(1), 34-65. Retrieved From Http://Www.Ex-Mba.Buu.Ac.Th/Research/Bkk/Ex-23Bkk/51721286/

Salam, A. A. \& Sahrah, A. (2019). Hubungan antara Adversity Quotient dengan Komitmen Organisasi pada Karyawan PT X Di Yogyakarta. Psikologi Umby.

Sambung, R. (2016). Dimensi Komitmen Organisasional: Dampaknya terhadap Perilaku Kerja pada Organisasi Sektor Publik. Jurnal Terapan Manajemen Dan Bisnis, 2(1), 28-37.

Sapruni. (2014). Pengaruh Pengembangan Sumber Daya Manusia untuk Mewujudkan Efektivitas dan Efisiensi Kerja Pegawai pada Dinas Perhubungan Komunikasi dan Informatika Kabupaten Poso. Jurnal Administratie, 03(September). Https://Doi.Org/Http://Dx.Doi.Org/10.1007/S15010-002$3027-8$

Satwari, T., Musadieq, M., \& Afrianty, T. (2016). Pengaruh Komitmen Organisasional terhadap 
Turnover Intention (Survei pada Karyawan Hotel Swiss-Belinn Malang). Jurnal Administrasi Bisnis S1 Universitas Brawijaya, 40(2), 177-186.

Siregar, L. M. (2015). Analisis Kepuasan Kerja dan Kualitas Pelayanan. (August), 89-99.

Suifan, T. S., Abdallah, A. B., \& Diab, H. (2016). The Influence of Work Life Balance on Turnover Intention in Private Hospitals: The Mediating Role Of Work Life Conflict. European Journal Of Business And Management, 8(20), 126-139. Retrieved From Www.Iiste.Org

Wahyuni, A. S., Zaika, Y., \& Anwar, R. (2014). Analisis Faktor-Faktor yang Memengaruhi Turnover Intention (Keinginan Berpindah) Karyawan pada Perusahan Jasa Konstruksi. Jurnal Rekayasa Sipil, 8(2), 89-95.

Widyantara, I. B. P., \& Ardana, I. K. (2015). Pengaruh Kepuasan Kerjadan Komitmen Organisasi terhadap Intensitas Turnover Karyawan. E-Jurnal Manajemen Unud, 4(6), 1670-1683.

Witomo, F. (2015). Studi Deskriptif Kepuasan Kerja Karyawan Bagian Administrasi pada PT. Karya Indah Makmur. 202-206.

Wonowijoyo, S. M. T., \& Tanoto, S. R. (2018). Pengaruh Organizational Commitment dan Kepuasan Kerja terhadap Turnover Intention di PT. Kediri Matahari Corn Mills. Agora, 6(1), 1-9.

Youcef, S., Ahmed, S. S., \& Ahmed, B. (2016). The Impact of Job Satisfaction on Turnover Intention by The Existence of Organizational Commitment, and Intent to Stay as Intermediates Variables Using Approach PLS in Sample Worker Department of Transport Saida. Management, 6(6), 198202. Https://Doi.Org/10.5923/J.Mm.20160606.03

Yui-Woon, W., \& Yui-Tim, W. (2017). The Effects of Perceived Organisational Support and Affective Commitment on Turnover Intention: A Test of Two Competing Models. Journal Of Chinese Human Resource Management, 8(1), 2-21. Https://Doi.Org/10.1108/Jchrm-01-2017-0001

Yulianti, P. (2015). Komitmen Organisasional Perspektif: Konsep Dan Empiris. Jurnal Studi Manajemen Dan Bisnis, 2(1), 52-62. 